\title{
More for Less? Sharing Economy as a Driver of Public Welfare Innovation
}

\section{Eva Pallesen and Marie Aakjær}

\author{
"It is... what can you say, like keeping together, right? You help each other \\ with small things."
}

User of digital platform for citizens with lung disease

\begin{abstract}
This article investigates sharing economy as a path to welfare innovation. It is based on a case where a digital platform is activated in order to support sharing among citizens with lung disease, and thereby increase health and wellbeing. The case exemplifies how sharing economy currently is taken up by public actors in the attempt to prolong the goals of the public sector beyond itself. This implies drawing everyday sharing practices into a new middle between formal organization and private relations. In a critical response to literature on sharing economy that tends to reduce 'sharing' to 'transaction', the article draws attention to how sharing entangles with hopes, fears, and affectual engagements of everyday life, and to how it interacts with technology in unforeseen ways and beyond anticipated outcomes. Based on the analysis, the article concludes that there may be good reasons for public welfare authorities to engage in facilitating sharing among citizens. This is not because it is likely to provide 'more for less' in relation to predetermined goals, but rather because it can open up other kinds of welfare outcomes that cannot be produced by public organizations themselves.
\end{abstract}

\section{Introduction}

The emergence of the term 'sharing economy' has evoked hopes for a more sustainable future, as well as fears of a rawer capitalism (Martin, 2016). In this context, the state is called upon in its capacity as regulator, which must counteract problems created by the sharing economy. Increasingly, however, the public sector is also called upon to renew and reinvent itself from the very model of sharing economy. In this context, 'sharing economy' not only refers to an emergent new economic order, but also to an organizational form that unsettles the state itself (Lovink \& Rossiter, 2019). The idea of 'sharing' as the digitally mediated distribution of access to underused resources, here comes into sight as a possible way to address the pressure of complex problems, ageing populations, and tight budgets that many western welfare states currently face (give\&take.eu; Vive, 2017).

In this article, we turn our interest to sharing economy as a form of organizing that simultaneously unsettles and creates new hopes for the welfare state. We investigate the idea of digitally mediated sharing as a path to welfare innovation based on a case where this idea is translated into (local) practice. While sharing economy has attracted substantial research attention as a new market form, 'sharing' as an activity that goes beyond the economic sphere, has not had the same scholarly attention (Belk, 2013, 2014; John \& Sützl, 2015). Studies of the public sector in relation to sharing economy have primarily focused on its role in a market context as regulator or user (Ganapati \& Reddick, 2018; Hofman et al., 2019), while the influence of sharing economy on the public sector itself as organizational form has had less research attention.

Consequently, we know more about regulatory challenges for public authorities and less about how sharing economy is translated into public sector practice, and how that matters in citizens' everyday lives. In the ambition of contributing to this question, we analyze a case where a Danish municipal healthcare unit engages in promoting a digital platform in order to enable sharing of care and welfare services among citizens with chronic lung disease. The case was generated as part of the Mature-project, based in a Danish municipality, which aims to co-design digitally mediated sharing within senior communities. 


\section{More for Less? Sharing Economy as a Driver of Public Welfare Innovation}

\section{Eva Pallesen and Marie Aakjoer}

With an explicit reference to sharing economy and senior citizens as possessing 'untapped knowledge and experience, time, and energy', the project sets out to provide 'scenarios for older adults as recipients, citizens, providers, and developers of future care and welfare services', that are considered to be a matter of 'survival of the welfare system' (Vive, 2017). Before turning to the empirical case however, we first contextualise the focus of the article in existing research literature, and address the methodological questions it implies.

\section{Research literature: sharing economy, technology, and the public sector}

'Sharing economy' as a term is often used interchangeably with 'collaborative economy' or 'platform economy', referring to a new economic order characterized by the rapid emergence of virtual platforms, that match individual suppliers of goods and services, with individual customers who demand these goods and services (Rochet \& Tirole, 2003). Hence, all three concepts refer to a break with traditional economy in the sense that 'firms transacting with individuals' is replaced with 'individuals transacting with individuals'. Although digital platforms are also part of traditional economy, in the sharing economy they gain a new centrality since they operate as a substitute for previous ways of relating suppliers, producers, and customers (Mair \& Reischauer, 2017).

However, to a larger extent than 'collaborative' or 'platform', the word sharing signals the promise of a kind of new social order. Thus, the emergence of sharing economies has given rise to hopes as well as criticisms: while advocates see it as a movement of reform and activism, opening up to new forms of emancipation and innovation (Acquier \& Carbone, 2018); critics on the other hand, question the idealized vision and see 'sharing economy' as a nice word concealing a rawer capitalism, where employment relations are destabilized and individualized (Scholz, 2016).

Stressing the heterogeneity of sharing economy, several typologies and definitions have been offered in the research literature (Acquier \& Carbone, 2018; Mair and Reischauer, 2017; Hamari et al., 2016). Hamari et al. (2016) link sharing economy to collaborative consumption, defined as "the peer-to-peer-based activity of obtaining, giving, or sharing the access to goods and services, coordinated through communitybased online services". The centrality of online mediation is also stressed by Mair and Reischauer (2017), who define sharing economy as "a web of markets in which individuals use various forms of compensation to transact the redistribution of and access to resources, mediated by a digital platform operated by an organization". The locus of sharing economy is here unambiguously identified as the market, the only difference being that payment is only one compensation form out of many, which in sharing economy may also include gift giving or bartering. They here subsume gift giving under the market context, while others have placed the sharing economy on a span between market economy and gift economy (Sundararajan, 2016). Mair and Reischauer's definition further stresses new access to, and distribution of goods already there, rather than the production of new ones. This highlights an aspect that links sharing economy to a sustainability agenda (Heinrich, 2013).

In this conceptualisation, it is regarded as a key feature of sharing economy that it creates new access to resources that are currently underused. The case analyzed in this article exemplifies how this aspect is currently picked up as an organizing principle, which can be applied as a strategy in public sector governance (give\&take.eu; Vive, 2017). In this context, the relation of technology and the welfare state is reconfigured.

Historically, the emergence of the western welfare state is intimately entangled with the history of technology. In the Scandinavian welfare states, where our empirical study is located, technological innovation was from the beginning deliberately supported as an instrument for enhanced prosperity, and as an approach in public social and healthcare policies (Klüver, 2005). The recent arrival of digital platforms, however, creates new roles and positions for welfare professionals (Nickelsen \& Elkjær, 2017). In activating digital platforms to facilitate sharing, the public sector's role is further altered with municipalities here positioned in parallel to the role of platform venture (Reischauer \& Mair, 2018). Rather than directly providing a service, they deliver a frame in which citizens can access and share services. 'Sharing' here represents the possibility to extend the goals of the public (for example, healthcare) organization beyond itself, by enabling citizens to share knowledge and services that contribute to the outcomes pursued by the public sector (for example, increased health and mobility for citizens), yet without the municipality necessarily being the service provider. Thus, in the notion of sharing economy as a path to welfare innovation, the everyday practice of sharing between people who trust one another is drawn into a new 


\section{More for Less? Sharing Economy as a Driver of Public Welfare Innovation}

\section{Eva Pallesen and Marie Aakjoer}

middle between formal organization and purely informal relations.

However, as emphasized by Belk $(2013,2014)$ and others inspired by Belk (John \& Sützl, 2015), the scholarly concept of 'sharing' as a specific kind of action distinct from gift giving or market exchange is underdeveloped, despite a recent rapid increase in research focus on digital sharing and sharing economy. 'Sharing' seems here to be implicitly couched in new forms of transaction (moving from 'individuals transacting with corporations' to 'individuals transacting with individuals'), which are accompanied by new forms of compensation (extending compensation into the nonmonetary). Relatedly, most of the work done on the sharing economy does not problematize the role of technology (Sutherland \& Jaharri, 2018) or "engage with its interactions with existing norms, cultures, or other important contextual elements" (Ibid, 2018).

Since the sharing economy is currently lifted up as a solution on challenges at a societal level, we find it urgent to study how this idea translates into practice. Furthermore, we find it important to do so without automatically inheriting the assumptions about sharing (collapsed with transaction) and the concept of technology (loosened from the political) that dominate the literature on 'sharing economy'. This implies the study of sharing as an everyday practice including its material, affective, and bodily aspects. In the next section, we address how we take up this ambition methodologically.

\section{Method}

\section{Methodology and analytical approach}

Moving from the general idea of sharing economy as a form of organizing to its micro-level poses some challenges to data collection and analysis. While the Mature project description talks about digital sharing of 'welfare services' and 'untapped resources', such things are more ambiguous in practice. We may thus ask: how can one locate the 'resources' being tapped and the 'welfare' being digitally exchanged?

In terms of methodology, however, this problem implies phenomenological interest (Holt \& Sandberg, 2011), that is, an urge to move from the abstract notion of 'digitally mediated sharing of welfare' to a focus on how sharing plays out in everyday life. This points to data collecting methods (such as observation and informal interviews) related to the ethnographic field (Ybema et al., 2009; Czarniawska, 2014) with its emphasis on 'being there' in the middle of things. In this case, 'being there' was twofold: it meant being there in digital space, having access to what was shared on the platform, as well as having access to situations where people using the platform meet off-line.

The emphasis on ethnographic data collection methods was also related to our aim of going beyond an entitative and instrumental approach to technology, which tends to position the digital platform as an isolated driver of predefined change. Instead, we have aimed to study the use of the digital platform in a way that does not exclude context, and not only focuses on what it is used for and when, but includes how it matters in the lives of participants, and how it evokes and is evoked by other components in people's everyday life.

Pursuing this aim, we have found situational analysis (Clarke 2003, 2005) helpful. Drawing on the tradition of Grounded Theory (Glaser \& Strauss, 1967), it places more emphasis on the relationality and co-constitution of assemblages of diverse components (Clarke, 2018). Inspired by situational analysis, we thus started out by creating situational maps, which, in accordance with Clarke's notion of this, laid out human, non-human, and other situational elements, focusing on analysis of the relations among them (Clarke, 2003).

Based on our interest in 'sharing' as a vital part of everyday life (rather than a limited activity of transacting), this mapping process implied listening carefully to the citizens' descriptions of daily life and to how (relations of) components emerge as significant to people. Inspired by Sarah Pink's (2009 conceptualization of analysis as "points in the research process, where there is a particularly intense treatment of research material", we sought to open up opportunities for citizens to take active parts as coanalysers in this creative intensity. By using statements and photos collected in the research process to evoke their reflections and listen to the connections they would make from the collected material to their everyday lives, we aimed to use empirical material such as interviews and photos not simply as representative, but as evocative (Pink 2009). Thus, our aim was to explore how statements and photos from one person or one situation may open up a path into the multiple and multisensory everyday experiences of other citizens. This, for example, meant attending to points in the workshop where many participants suddenly react (nod, sigh, or speak at once). 


\section{More for Less? Sharing Economy as a Driver of Public Welfare Innovation}

\section{Eva Pallesen and Marie Aakjoer}

\section{Empirical material and data collection}

The analysis draws on material from the research and development project Mature, more specifically a part of the project: Work Package 3 (WP3). This Work Package was designed with inspiration from another project, the Give\&Take-project (Give\&take.eu), in which the aim was to co-design digitally mediated sharing among seniors in Denmark and Austria, with citizens exchanging services and resources. In WP3, this was translated into a local setting, a Danish municipality that had already made efforts to connect people (off line) with chronic lung conditions, in particular Chronic Obstructive Pulmonary Disease (COPD). The senior citizens attending the municipality's exercise activities for people with lung disease were contacted and asked whether they would find any interest in trying out what a digital platform might do to support their interactions. The platform allowed both group postings as well as individual messages. The municipality was active in implementing the digital platform, which was in practice conducted by the coordinator organizing the municipal services for people with lung disease.

The empirical material was gathered throughout a period of one year (September 2017- September 2018), based on a qualitative in-depth study of 11 citizens with access to the digital platform. It encompasses semistructured interviews, informal conversations, and observations from citizens' physical gatherings (in total 21 interviews or observations) as well as data from interactions on the platform, including the number of sent and read messages. The number of 11 citizens obviously poses a quantitative limitation to the study; consequently, the empirical material is not suitable for identifying generalizable causal relationships and explanations. Instead, the study aims at contributing to the qualitative understanding of practices that are always situated and local. The workshop, arranged after seven months of access to the platform, was a way to extend the qualitative 'thickness' of the material by putting excerpts from interviews with and observations by the 11 citizens into play among a larger group of citizens.

\section{Analysis: Sharing in the everyday context of chronic disease}

The following presentation of data is organized around what was shared, or intended to be shared. However, as shown in the analysis, the question of 'what' was actually shared can be discussed. Information, tools, and maps are not simply isolated entities being transacted among citizens, but rather components that interact in different ways with other components, including the hopes, fears, and affectual engagements of everyday life. The analysis draws attention to how sharing emerges in this kind of interaction, rather than in the transaction alone. It also points to the municipality as just one component among other components, that interact in unforeseen ways and beyond anticipated outcomes.

\section{Sharing maps}

An idea that immediately attracted peoples' attention was discussed also offline. It involved the possibility of sharing maps of local walking routes digitally, then inviting people online for a walk via the platform:

User 1: I know some people are troubled with the long routes and where you start and all that. You could make different [walking] routes. And make some routes where you could sign up to join. For example, on the platform, then we could make some routes from the local area, which would fit everyone, depending on the capacity you have (...)

User 2: There is no place like [the local area] where there are some fantastic routes in nature, where there are many possibilities to walk. We could make suggestions of routes with different lengths for example, I walk a lot out on the reef...

User 3: (breaks in): ... but there! -I don't dare to walk at all at such places where there's no access for an ambulance or where I cannot receive help if I get in trouble. I don't dare walk there -it is out of question! In my case - I simply cannot go there! [a lot speak at once; somebody suggests a route and several add 'there is also the fort...' ' '...or just a walk on the beach' or 'I think...']

The idea discussed here explicitly resonates with the Mature-project's aims and hopes of enabling the sharing of health-promoting initiatives, related to the specific condition of lung disease, like on platforms such as 'Give \& Take'. However, in this conversation about the possibility of sharing walking routes on the platform, it is also clear that this cannot be reduced to a question of exchanging detached knowledge of landscape as a site for exercise (levels of difficulty, hills, and inclines). It is also entangled with everyday life and may catalyze previous experiences, for example, on how a specific geographic location has appeared inaccessible and isolated in the context of lung disease.

Noticeably, this idea about walking routes returns repeatedly in conversations addressing the possibilities 


\section{More for Less? Sharing Economy as a Driver of Public Welfare Innovation}

\section{Eva Pallesen and Marie Aakjoer}

of the digital platform.; However, as long as data collection lasts, this remains an exercise of collective dreaming, driven forward by suggestions starting with 'you could easily...' 'and then we could...', turning into then 'it doesn't have to be that hard', and other expressions on the way to eventually making the technical attempt. People repeatedly return to the possibility of the digital platform; however, to our knowledge they actually do not go out walking on these specific routes as a result of maps shared on such a platform.

Thus, the project assumption (or hope) was that citizens would be attracted to the platform community by the knowledge or service they can get or share (exchange) there. However, rather than being a tool for an actual exchange of knowledge or service, in this case the platform functions as a driver of a collective sense of possibility. It allows users to hold on to the feeling that the world is still worthy of new plans in the context of serious chronic disease. Thus, rather than just enabling an exchange, the digital platform evokes an 'expectant forward looking' (collective dreaming) as well as a reactivation of past experience and anxiety, both of which reach beyond an instrumental exchange of information.

The 'sense of possibility' seems to be a vital aspect whenever the point in being connected on the digital platform is addressed by Users:

User: I can still see the point in being on Facebook or on the computer [digital platform], right? (...) I can easily think of, if I sit home a day, maybe a Sunday afternoon and the weather is nice, I would like to go out for a walk. Might there be somebody I could invite? Might there be somebody who could invite me ? I could do that. ... Or if somebody hasn't been here, I haven't seen for a long time, I can just write them: 'Hey, how are you?' 'Is it really bad or are you just on holiday'?

Thus, the digital platform produces a feeling that there are always others 'out there' to reach out to. Notably, this feeling also seems to matter on days when reaching out is not actually carried out. This indicates that sharing practices are constituted more diffusely in interaction with expectations and anticipation, rather than only in the actual transaction of 'something' .

\section{Sharing information}

From the perspective of information and services exchange, one could have expected that information sharing among citizens would be centred around lung disease, which is the condition the Users have in common and need help to handle. What we see in the material, however, is that Users do not, to any significant degree, share factual information about their illness, neither online nor offline. Some Users explicitly state that they are repulsed by, rather than attracted to, digital platforms where information on illness is shared:

User 1: But I will also say that I rarely enter it [COPD patient association's digital platform] because sometimes, all that illness just makes me sick, because you don't...

User 2: No, you don't have the energy, do you?

Thus, the presupposition that Users will be attracted to the digital platform by the information they can get or share there related to a specific health condition, is often more ambiguous in practice. The examples of such sharing that we saw on the platform, almost exclusively came from the municipality (more precisely the employee coordinating activities for citizens with chronic lung disease). While the municipal coordinator tried to push forward information links on COPD and instructions for exercises on the digital platform, this did not attract unambiguous attention from the users, as exemplified in the following observation note from a setting where the coordinator meets with platform users after the exercise session:

The coordinator asks if anybody saw the television program about COPD. It was about health and COPD. He has shared the link on the digital platform. Nobody has seen it. One of the citizens takes up his tablet, but he has trouble connecting it to the WIFI of the municipal activity centre. The coordinator walks to his place. Meanwhile, a woman says that now she is excluded; she cannot get linked to the platform, and now everything will happen there. She has a brain injury, and cannot remember from one moment to the next the instructions she is given on how to be linked to the platform. She has now thrown out the computer. 'Once you got pictures of grandchildren on paper, but now everything is on the phone or the computer', she says. The coordinator says that she will not be excluded, 'we can still meet physically', he adds.

While the municipal coordinator uses the platform to share a link to specific knowledge, it does not attract much attention, except from one woman who speaks up. However, it is not simply the information itself - the specific television programme - that seems important to 


\section{More for Less? Sharing Economy as a Driver of Public Welfare Innovation}

\section{Eva Pallesen and Marie Aakjoer}

her, but rather the sense that she is now about to be excluded from what is going on where 'everything will happen'. In contrast with a paper photo of one's grandchildren, which one can hold in their hands, accessing the digital depends on being successfully linked.

Like information and memories in a damaged brain, the digital is here felt as fragile and elusive, almost unreliable. Hence, just like access to a digital platform may produce a sense of possibility of something that is yet to come, it may also produce a sense of being cut off from an emergent future. The platform evokes joyful expectation, as well as a sense of being repelled or excluded. Thus, its interaction with other components in citizens' everyday lives has aesthetic as well as political aspects, rather than purely instrumental ones.

\section{Sharing tools}

The Mature project was inscribed in an agenda about activating digital platforms that allowed senior citizens to share, not only knowledge, but also services and care. Hence, they could be positioned as both 'providers' and 'receivers' of welfare services, similar to individuals being both suppliers and demanders in the case of platform ventures. And there are examples in the material, where users share specific aids related to their condition:

User: Take for example Gerda: I have difficulties getting down to my shoes, they have become so far away down there. Gerda noticed and brought a shoehorn that can help her change from sneakers to boots. Damn, that is lovely isn't it?

Interviewer: So, you understand those details and what is difficult for the others?

User: It is ... what can you say, like, keeping together, right? You help each other with small things.

The actual aid that the user in this example gets (the shoehorn) is so entangled with mundane aspects of life ('small things') that it is almost not visible from the abstract vantage point of Mature's project description, which talks about 'welfare services' and 'untapped resources'. Putting on shoes normally falls unproblematically into the background of everyday life; however, in the context of reduced respiratory capacity, the shoes suddenly become visible 'far away down there'. The shoehorn - an everyday tool mediating the body and the shoes - is here passed on from Gerda to another user. Noticeably however, this sharing does not simply emanate from the two being isolated users connected on the digital platform; it is conditional on a process that emerges from recurrent physical copresence. Gerda observes another user having a problem in the context of their bodily co-presence. Prompted by shared experience (she knows how it feels) and affectual attachment (she is emotionally tied to and cares for the other), she remembers it as she gets home to her own shoehorn and brings it the next time they meet.

Rather than replacing physical co-presence and existing everyday technologies, the digital platform interacts with these in a process where emotional attachment and valuation of singularity are key aspects. Although several users explicitly state that they are not private friends with other users, sharing does not take place among interchangeable, anonymous users mediated by the platform. Instead, it relies on a communization process in which belonging and interdependency prevails (Vaujany et al., 2019).

\section{Sharing coffee}

Thus, in the sharing practices that emerge among senior citizens with access to the digital platform, physical copresence does not cease to be important. On the contrary, there is one kind of sharing, stressed by the users themselves, that we had almost overlooked in all its mundanity. In the workshop, a number of photos from fieldwork and statements from interviews with the users were placed on the table and they were asked to pick up a card representing something vital in their interaction with other COPD patients. Here, the keyword was coffee rather than 'information', 'service', or 'care':

User: I have chosen this [photo] where we sit down and have coffee together afterwards [after the exercise session organized by the municipality]. And then that statement (reads from a piece of paper) 'First we buy a pot of coffee and then we have a cozy time and talk about how things go along and what each other will do and have done'. Instead of here [the off-line workout session organized by the municipality] we are sometimes told to shut up, right? (scattered laughter)

Interviewer: So, it's about getting to talk with each other?

User: It is. It means a lot. 


\section{More for Less? Sharing Economy as a Driver of Public Welfare Innovation}

\section{Eva Pallesen and Marie Aakjoer}

In relation to the overall agenda of rescuing the welfare state, all of this talk about coffee may seem very mundane. As indicated in the quote however, gathering around coffee is simultaneously a more open and intimate form of sociality than the workout sessions organized by the municipality as a way to enhance respiratory capacity. In the latter, talk and jokes, which are not related to the aims of the exercises, are closed down (smoking pauses were banned as well). In contrast, in the open form of sociality organized around coffee, the aim of being together is less explicit and more open to what role one participates in. Participation itself can have other forms than being physically or conversationally active, as illustrated when a user explains why she appreciates sharing coffee with the others:

User: It is good to hear about others' everyday life. How everyday time is spent. Where you talk about ... a crossword puzzle, right? I actually like to relax and just listen to that. You don't have to talk yourself, but you can absorb some of it [several nods, adds a 'yes']. In any case, I do.

Hence, one could say that it is actually not so much coffee itself, which is shared in the interactions around coffee. Rather coffee is that which organizes sharing in a certain way. When users share coffee together, they do not only offer coffee to each other; they offer themselves for others to be with in an open-ended setting. This enables a certain (relying, listening) mode of engagement that sets aside specific expectations regarding the situation's outcomes and produces a readiness for opening up oneself to let in ('absorb') some of the world. However, this also reveals vulnerability:

User 1: It is also about following each other ... if there is somebody who doesn't turn up one day. Wonder ... (U1 and U2 simultaneously) what has happened to them?

User 3: What is happening and why didn't they turn up? It is like thinking about each other how...

User 1: (continues) ... how each other... like... how far are they? It is not so much that we talk about illness. I don't like it either.

A large part of the material addresses the feeling of vulnerability related to the other's death or serious illness:
User 1: That is the toughest part. When people don't show up, well.

User 2: It is also...

User 3: It is not to bear, is it? (...) Hell, it hurts [many speak at once]

Thus, sharing around coffee is not so much centred around the illness-health distinction (in contrast to the municipality's exercise program); rather it relates to the death-life tension.

The introduction of the digital platform was an attempt to prolong the goals of the public sector beyond itself by activating everyday sharing for a health-promoting purpose. However, everyday sharing does not simply revolve around the same distinctions as public welfare services. In the latter, physical exercise belongs to one side (health promoting factors), while cigarettes and schnapps (which were also shared among users) belong to the other side (health hazardous factors). In everyday sharing however, they can both be components in the same purpose: to feel alive and connected in the context of vulnerability.

\section{Discussion: Sharing economy as a driver for innovating welfare services}

While the digital platform is promoted by the municipality with the explicit intention of prolonging the goals of the public healthcare unit, this is pursued by enabling processes and practices that are more porous and contingent than the public organization itself. The interactions revolving around the platform are framed less by fixed goals and roles than the formal organization implies. But they are still more formally organized than purely informal relationships in the users' lives.

Thus, in taking up sharing economy as a path to welfare innovation, the everyday practice of sharing is drawn into a new middle between formal organization and purely informal relations. The public welfare system remains in the picture via the municipality's active role in promoting the platform, while the municipal coordinator is only there as one component among other components, which are not linked to each other within a hierarchical order bound for a specific service production. While the relations of the formal (public) organization of the municipality are pre-coded into certain goals and roles, the relations among the 


\section{More for Less? Sharing Economy as a Driver of Public Welfare Innovation}

\section{Eva Pallesen and Marie Aakjoer}

components in the emerging network among citizens with chronic disease are temporarily and contingently attached to each other. Rather than an organizational hierarchy, we could speak of a qualitative assemblage (Hjorth, 2014) in which heterogeneous elements such as digital platform, base location, coordinator, coffee, dreams, fears, and diagnosis interact in unpredictable ways and with unknown outcomes.

In this context, the relation of technology and public sector is multiplied. Rather than primarily being one of strategic instrumentality, it has become more contingently constituted in assemblages implying new positions for public sector agents. Notably, however, the analysis on the previous pages exemplifies sharing practices that have taken place on the limits of technology in the hands of the welfare state. In particular, when illness strikes in unforeseen and unfair ways, or when death lures and fear intensifies, that is, when vulnerability prevails. This especially draws attention to sharing as an everyday practice that precisely thrives at the point where generalizable laws and predetermined goals are no longer applicable, and where emotional attachment and valuation of singularity are key aspects.

The digital platform does play a role at this threshold, but not simply as a tool for redistribution of 'untapped' resources in the service of 'accelerating' known outcomes. Rather, it catalyzes dreams of future connections as well as driving fears for relations that may slip away. In this context, technology comes into play among other interrelating components in the users' lives, evoking imagination and forward thinking as well as past experience in unforeseen ways and with unknown outcomes.

Hence, it raises questions about the possibilities for shared living that are enabled by technological mediation, and who will be included or left out. Furthermore, it suggests that there are limitations in activating sharing as part of continued rationalisation of the welfare state, since sharing precisely unfolds at the limits of means-ends rationality. However, because of this, the public sector can, by engaging in facilitating (digitally mediated) sharing among citizens, open up a space in-between formal organization and private relations in which other kinds of welfare outcomes emerge, such as a 'sense of possibility' in the context of severe chronic disease.

\section{Conclusion}

Sharing economy does not simply represent the possibility of getting 'more for less' in a public sector context, since sharing as an everyday practice precisely thrives at the limits of predetermined goals, roles, and outcomes. In this article, we have aimed at contributing to an understanding of sharing not only as a limited transaction, but also as a vital aspect of everyday life. In this view, sharing is both before and beyond the state, and hence marks the 'other' that it lives and develops from. That is, however, also the very basis for the innovative potential in relation to government. By actively facilitating online and offline sharing within specific citizen groups, the public sector can initiate a new middle between formal organization and private networks in which 'other' forms of felt welfare are enabled that cannot be produced by formal organization itself. Nevertheless, this also raises new questions about how digital mediation is reframing our understanding of sharing as an everyday practice, and urges public sector agents to attend to - not only the instrumental - but also the political and aesthetic aspects of digitally mediated sharing, when it is put to work in a welfare context.

\section{References}

Acquier, A., Carbone V. 2018. Sharing economy and social innovation", in The Cambridge Handbook of the Sharing Economy and Law, ed. Davidson, Finck \& Infranca.

Belk, R. 2013. You are what you can access: sharing and collaborative consumption online. J Bus Res 67:1595-1600.

Belk, R. 2014. Sharing Versus Pseudo-Sharing in Web 2.0. The Anthropologist, 18(1): 7-23.

Clarke, A. 2003. Situational Analyses: Grounded Theory Mapping After the Postmodern Turn. Symbolic Interaction, 26(4), s.: 553-576.

Clarke, Adele E. 2005. Situational analysis: Grounded theory after the postmodern turn. Thousand Oaks, CA: Sage.

Clarke, A.E., Friese, C. \& Washburn, R.S. 2018. Situational Analysis: Grounded Theory After the Interpretive Turn. Thousand Oaks, CA: Sage.

Czarniawska, B. 2007. Shadowing: And Other Techniques for Doing Fieldwork in Modern Societies. CBS Press.

Ganapati, S. \& Reddick, C.G. 2018. Prospects and challenges of the sharing economy for the public sector. Government Information Quarterly, Volume 35, Issue 1, January: 77-87. 


\section{More for Less? Sharing Economy as a Driver of Public Welfare Innovation}

\section{Eva Pallesen and Marie Aakjoer}

Glaser, B.G., \& Strauss, A.L. 1967. The discovery of grounded theory: Strategies for Qualitative Research. Chicago. Aldine Publishing Company.

Hamari, J., Sjöklint, M., \& Ukkonen, A. 2016. The sharing economy: Why people participate in collaborative consumption. Journal of the Association for Information Science and Technology, 67(9): $2047-2059$.

https://doi.org/10.1002/asi.23552

Heinrich, H. 2013. Sharing economy: a potential new pathway to sustainability. GAIA 22/4: 228-231.

Hjorth, D. 2014. Entrepreneuring as Organizationcreation. In: Sternberg, R. \& Kraus, G. (Eds.) Handbook of Research on Entrepreneurship and Creativity, Cheltenham: Edward Elgar: 97-121.

Hofmann, S, Sæbø, Ø, Braccini, M \& Za, S. 2019. The public sector's roles in the sharing economy and the implications for public values. Government Information Quarterly, Volume 36, Issue 4, October.

Holt, R., \& Sandberg, J. 2011. Phenomenology and Organization Theory, in Tsoukas, H. and Chia, R. (Ed.) Philosophy and Organization Theory, Research in the Sociology of Organizations. Vol. 32), Emerald Group Publishing Limited.

John, N.A. \& Sützl, W. 2015. The rise of 'sharing' in communication and media studies. Information, Communication \& Society.

Klüver, P.V. 2005. Technology transfer, Modernization, and the Welfare State. In: Bubenko J., Impagliazzo J., Sølvberg A. (eds), History of Nordic Computing. HiNC 2003. IFIP International Federation for Information Processing, vol 174. Springer, Boston, MA.

Lovink, G., \& Rossiter, M. 2019. Afterword: Propositions on the Organizational Form. In Beyes, T., Conrad., L., \& Martin, R. Organize. University of Minnesota Press.

Mair, J., \& Reischauer, G. 2017. Capturing the dynamics of the sharing economy: Institutional research on the plural forms and practices of sharing economy organizations. Technological Forecasting and Social Change, May 2017.

Martin, C.J. 2016. The sharing economy: A pathway to sustainability or a nightmarish form of neoliberal capitalism? Ecological Economics, vol. 121, January: 149-159.

Nickelsen, N.C.M., \& Elkjaer, B. 2017. Shifting boundaries in telecare-the nurse-doctor relationship. Journal of Workplace Learning, 29.7(8): 588-600

Pink, S. 2009. Doing Sensory Ethnography. Thousand Oaks, CA: SAGE.

Reischauer, G., \& Mair, J. 2018. Platform organizing in the new digital economy: revisiting online communities and strategic responses. Research in the Sociology of Organizations, Volume 57: 113-135.

Scholz, T. 2016. Platform cooperatism. Challenging the corporative sharing economy. Rosa Luxemburg Stiftung. New York Office.
Sundarajan, A. 2016. The Sharing Economy. The End of Employment and the Rise of Crowd-Based Capitalism. MIT Press, Cambridge, Massachusetts.

Sutherland, W., \& Jaharri, M.H. 2018. The Sharing Economy and Digital Platforms: A Review and Research Agenda. International Journal of Information Management, 43.

Vive (The Danish Centre for Social Science Research). 2016. MATURE - Meeting the challenges in population aging through innovation and culture adaption of welfare society.

Ybema, S.B., Yanow, D., Wels, H., \& Kamsteeg, F.H. (Eds.) 2009. Organizational ethnography: Studying the complexities of everyday life. London: Sage.

\section{About the Authors}

Eva Pallesen is Docent (Senior Associate Professor), $\mathrm{PhD}$ in Center of Management and Experience Design at University College Absalon, Denmark. Her research focuses on welfare innovation, management and entrepreneurship in the public sector. She has published in international journals such as Organization Studies and Methodological Innovations. Before entering academia, she worked as Head of Methodology Department in the Danish Evaluation Institute and as Head of Section in the Danish Ministry of Education.

Marie Aakjær is Associate Professor, $\mathrm{PhD}$ in Center of Management and Experience Design at University College Absalon, Denmark. Marie has a background in design and her research areas cover social innovation, learning and co-creation with particular interest in the interaction among citizens, civil society and public sector organizations. She has published in international journals such as International Journal of Entrepreneurship and Innovation Management and Qualitative Research in Organizations and Management.

Citation: Pallesen, E., Aakjær, M. 2020. More for Less? Sharing Economy as a Driver of Public Welfare Innovation. Technology Innovation Management Review, 10(5): 19-27.

http://doi.org/10.22215/timreview/1353

Keywords: Sharing economy, technology, innovation, welfare (cc) BY state, public sector. 